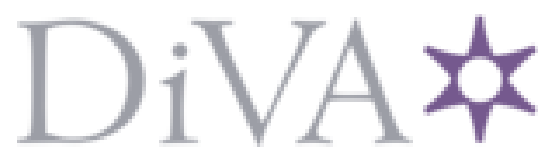

http://www.diva-portal.org

This is the published version of a paper presented at Sustainable development if energy, water and environment systems / 2011 / Croatia, SDEWS-11.

Citation for the original published paper:

Öhman, H. (2011)

Implementation and evaluation of low temperature waste heat recovery power cycle using NH3 in an organic rankine cycle.

In: Zvonimir Guzovic (ed.), Zagreb: Faculty of Mechanical Engineering and Naval Architecture

N.B. When citing this work, cite the original published paper.

Permanent link to this version:

http://urn.kb.se/resolve?urn=urn:nbn:se:kth:diva-188001 


\title{
Implementation and evaluation of Low Temperature Waste Heat Recovery Power Cycle using NH3 in an Organic Rankine Cycle.
}

\author{
H. Öhman \\ Department of Energy technology \\ Royal Institute of technology, Stockholm, Sweden \\ e-mail: henrik.ohman@rotor.se
}

\begin{abstract}
With increasing cost for power generation the opportunities for small scale power generation from waste heat have increased. The awareness of untapped resources such as local waste heat streams as well as the available range of technology and products to harvest such streams is increasing steadily. For ORC power plant applications the number of open parameters is large though the reported field data is limited, particularly for low temperature waste heat recovery.

This paper presents field data and a performance analysis of an ORC power generation plant operating with NH3 as media. The ORC unit operates on waste heat from a Swedish pulp mill at an available temperature level of 75 to 85degC. Performance at low waste heat temperatures and during capacity variation is reported as well as an analysis of the particular investment case.

The field data was generated by remote logging of control system information during a 15 day period.

The results show a thermal efficiency of 8 to $9 \%$ during a capacity range of 50 to $100 \%$ power generation. The results indicate a flat thermal efficiency curve from 20 to $100 \%$ power generation.

The investment case is a supplier own-and-operate type of arrangement supplying the pulp mill with electric power at a predefined cost during a long period of time.
\end{abstract}

\section{Nomenclature}

$\begin{array}{ll}\text { WHR } & \text { Waste Heat Recovery } \\ \text { LTPC } & \text { Low Temperature Driven Power Cycle } \\ \text { NPO } & \begin{array}{l}\text { Net Power Output (Electric work minus parasitic losses inside } \\ \text { the defined system) } \\ \text { Thermal efficiency (NPO/Heat rejected from heat source) } \\ \eta_{t h e r m} \\ \eta_{c l}\end{array} \\ \eta_{c, I l}=\frac{1}{n} \sum_{i=1}^{n} \eta_{c l i} & \begin{array}{l}\text { Local Carnot Efficiency in an infinitesimal heat exchange } \\ \text { between heat source and heat sink }\end{array} \\ \text { FoC }=\frac{\eta_{t h e r m}}{\eta_{c I}} & \begin{array}{l}\text { Integrated Local Carnot Efficiency } \\ \left.\alpha_{1}=\frac{1}{\left(\dot{\mathrm{m}}_{1} * \mathrm{Cp}\right.}\right)\end{array} \\ \text { Fraction of Carnot }\end{array}$




$$
\alpha_{2}=\frac{1}{\left(\dot{\mathrm{m}}_{2} * \mathrm{Cp}_{2}\right)} \quad \text { Heat sink inverse of thermal capacity }[\mathrm{K} / \mathrm{kW}]
$$

\section{Introduction}

Small scale local power generation using waste heat have become increasingly economical due to technology maturity, increased electric prices and increased competition among suppliers. In applications using waste heat below $100^{\circ} \mathrm{C}$ few commercial installations have been reported. Several geothermal ORC-plants using the now banned fluid R114 as well as more modern synthetic ones have been reported, such as [1. Brasz, J.J., Holdmann, Gwen. 2005] have been published.

One of the trade-offs regarding Organic Rankine Cycles, ORC, is the issue of operating fluids. The synthetic fluids, such as silicone oil, R245fa and R134a suffer from being excessively priced as well as having some environmental drawbacks. To make things worse ORC's often require large filling amounts as the heat exchangers need to be large.

Several of the ORC suppliers are therefore investigating the use of naturally occurring substances such as hydrocarbons, NH3 and CO2.

This paper show typical performance of an ORC-plant using NH3 in an industrial waste heat recovery application.

\section{MUNKSJÖ pulp mill WHR situation}

\section{Plant facts}

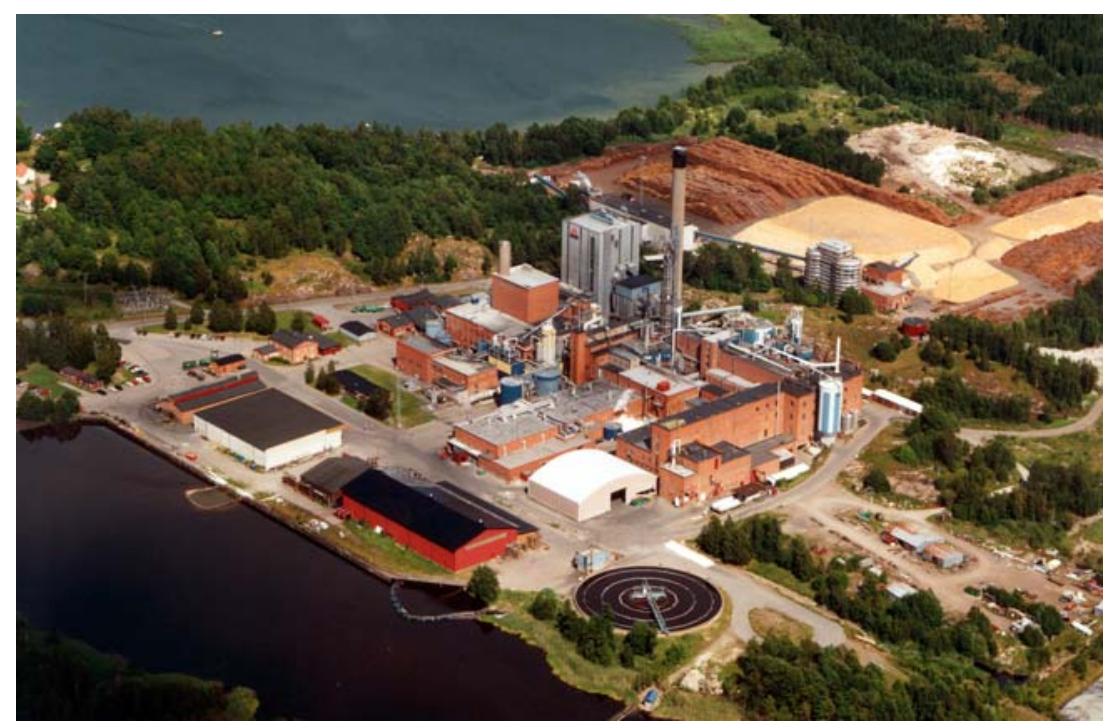

Fig 2. The MUNKSJÖ paper mill at Aspa.

The mill produces bleached and unbleached pulp at a capacity of 200.000tons/annum. It is located by the lake Vättern with yearly water temperatures according to Table 1

Table 1. Cooling water temperature at plant

\begin{tabular}{|l|l|l|l|l|l|l|l|l|l|l|l|}
\hline Jan & Feb & Mar & Apr & may & Jun & Jul & Aug & Sept & Oct & Nov & Dec \\
\hline 3 & 2 & 6 & 8 & 13 & 16 & 21 & 21 & 14 & 8 & 5 & 4 \\
\hline
\end{tabular}




\section{Waste heat source characteristics}

The heat source is a waste water stream originating from several parts of the manufacturing processes.

The waste water temperature is stable though the flow rate varies significantly. The water has to be cooled in order for the bio treatment systems to operate which is required by regulations.

The waste water contains contaminants such as lignin, fibres and other waste compounds with a PH of roughly 5,7. The relative content of waste compounds varies with fluctuations in the paper production process.

\section{Heat sink characteristics}

The chosen heat sink is a duct of lake-water already installed at the plant. A maximum rate of $720 \mathrm{~m} 3 / \mathrm{h}$ is available for cooling of the WHR-unit.

\section{ORC power plant}

The ORC power plant was supplied by Opcon under the brand name Opcon Powerbox.

Opcon Powerbox is a modularized range of ORC power plants utilizing waste heat as prime energy source, producing up to 750kWel NPO, se below.

The power plant is a self sustained "container"-type structure, fully automated and remote controlled.

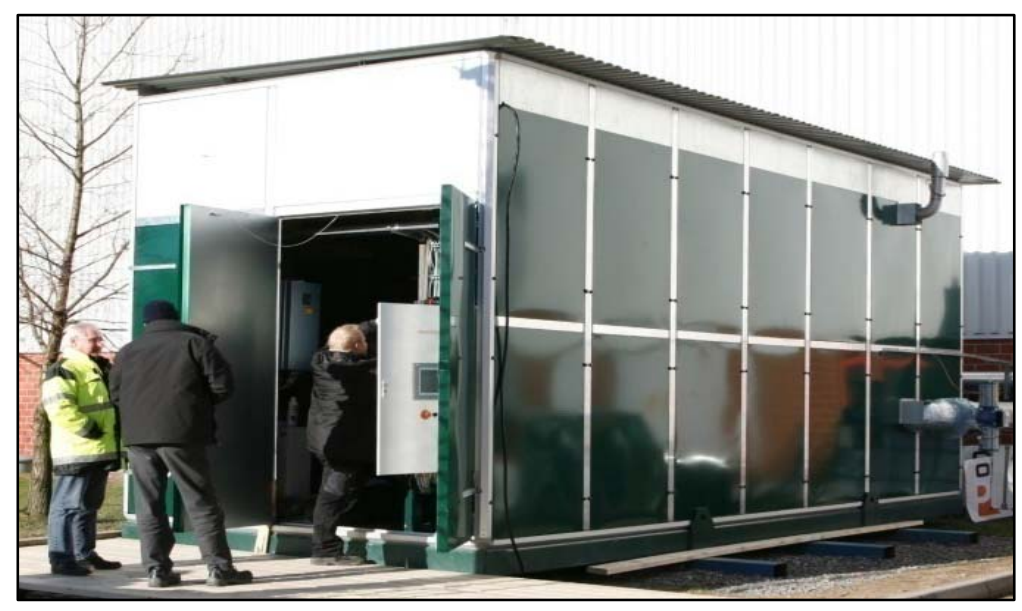

Fig 1. Opcon Powerbox.

The ORC consists of a closed loop of circulating NH3. Heat is drawn from the source by first preheating pressurized liquid followed by boiling without any superheat. The NH3 gas is expanded to a lower pressure in a Lysholm type turbine which transfers shaft work to a synchronous electric generator. The mixture of liquid and gaseous leaving the turbine is condensed by emitting heat to the cooling water heat sink. After condensation the liquid is pumped to the higher pressure to be preheated thus completing the cycle. [2. Öhman, H. Hedebäck, P. 2008] 


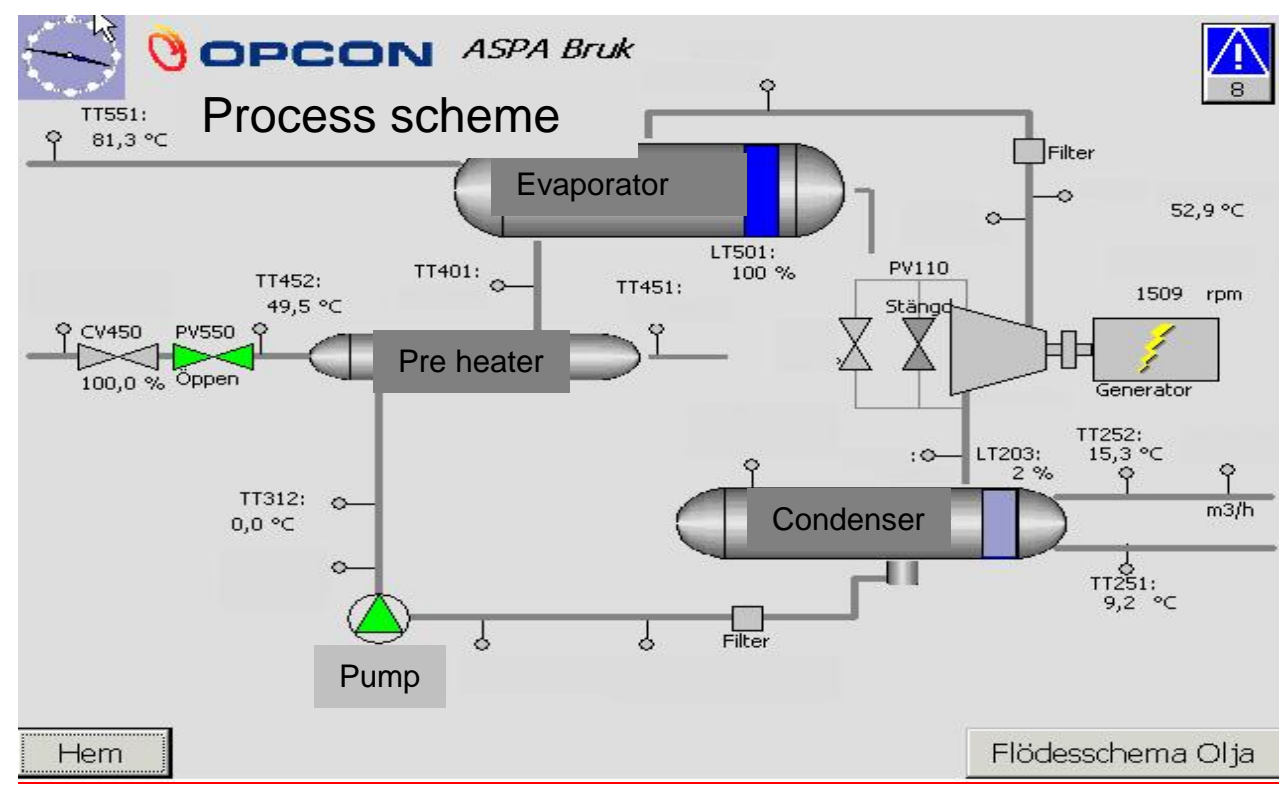

Fig 3. The ORC-system in an Opcon Powerbox.

Technical data for Opcon Powerbox ORC power plant

\begin{tabular}{|c|c|c|c|}
\hline Power & $950 \mathrm{kVA} / 50 \mathrm{~Hz}$ & Length & $11 \mathrm{~m}$ \\
\hline Voltage & $500 \mathrm{~V}$ & Height & $4 \mathrm{~m}$ \\
\hline Generation & Synchronous & Width & $3,5 \mathrm{~m}$ \\
\hline Media & NH3 & Heat source & Waste water \\
\hline Weight & $27.000 \mathrm{~kg}$ & Heat sink & Lake water \\
\hline
\end{tabular}

Table 2. Technical data for the Opcon Powerbox in Aspa

\section{Power Controls}

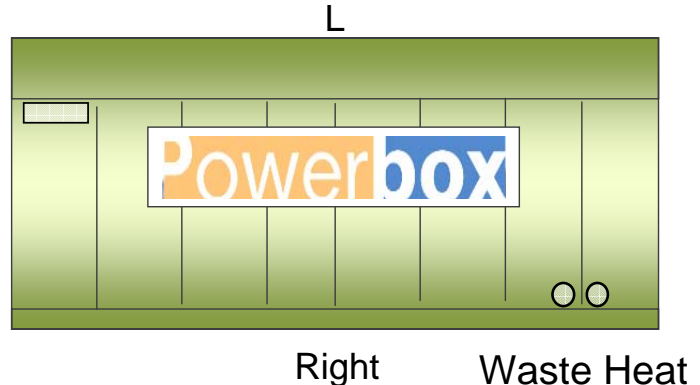

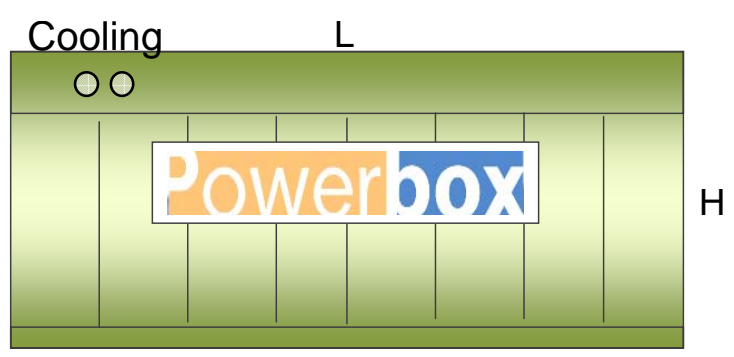

Left

Fig 4. Schematic view of an Opcon Powerbox

\section{Ammonia}

The choice of NH3 as the preferable operating fluid required some minor changes to the product, previously only supplied with synthetic fluids. The main changes where material compatibility of heat exchangers, pipes and polymer seals, higher class of corrosion resistance, enhanced worker safety protection and significantly more comprehensive operating, safety and service documentation. 
The legal workload was mainly limited to a municipality registration of NH3-storage, a renewed plant safety assessment and a registration at the National Energy Board for power supply to the grid net.

As the unit is remotely operated with all access points locked the safety assessment of the application became surprisingly straight forward.

\section{Lysholm Turbine}

The expansion device used in the ORC plant is a positive displacement type, twin rotary, helical body machine invented by the late Professor Alf Lysholm in the 1920's. The technology bears some generic similarities to screw compressors though the design differs significantly between a similar capacity turbine and compressor. The particular Lysholm Turbine used is designed and built by the leading industrial technology centre for screw machines and technology licensor Svenska Rotor Maskiner AB in Stockholm, Sweden. [3. SRM. 2008]

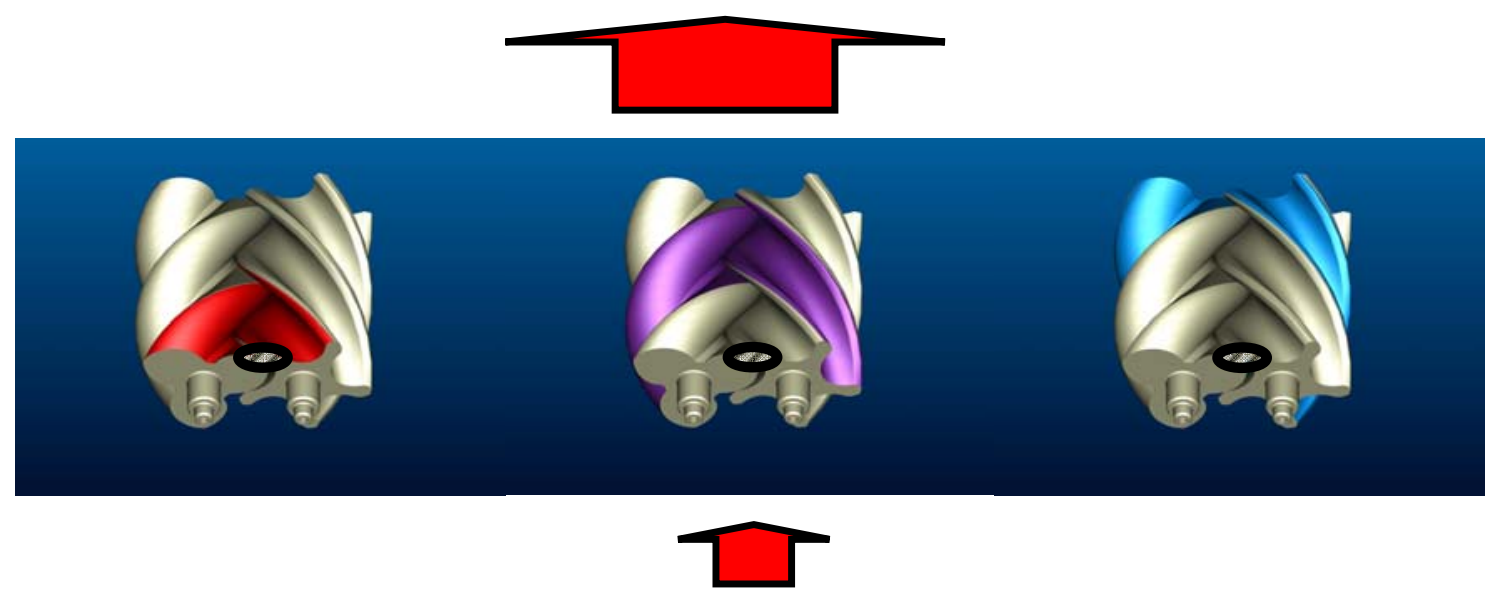

Fig 5. Visual operational mode of a Lysholm turbine. From left to right: Filling of pressurized 2-phase fluid through drilled hole in casing (oval), fluid expansion and simultaneous boiling in expansion chamber, discharge of 1 - or 2 phase fluid through drilled hole in casing (backside).

The advantage with Lysholm turbine characteristics in LTPC is that the preferred operating condition is a mixture of liquid and gas. (The use of Lysholm Turbines has traditionally been limited to two-phase or three-phase humid air expansion and wet steam expansion.) This allows the ORC to operate without superheating the NH3-gas, in turn allowing a higher boiling temperature with consequently higher system efficiency. Note particularly the insensitivity to "liquid slugging" in the case of transient operating conditions.

Another reason for the choice of a Lysholm Turbine is the relatively flat efficiency characteristics when exposed to a wide variety of operating conditions. [4. Öhman, H 2004] In the same reference a Lysholm turbine with $100 \%$ liquid inlet fluid is reported. The turbine used in this article however was limited to max $85 \%$, by mass, liquid inlet fluid.

The Lysholm Turbine is one of very few available multi-phase turbines in its size. Dynamic turbines suffer poor efficiency and blade wear using large contents of liquid inlet fluid. Piston motors generally suffer from "slugging" when liquid is injected. Some alternatives for multiphase flow expansion exist for powers below $20 \mathrm{~kW}$ though the author was unable to find other industrially available 2-phase turbines in the same range as reported in this article. 


\section{WHR performance}

After commissioning and extended performance tests the unit has been in remote, selfautomated operation from the autumn of 2010.

\section{Practical aspects}

Several practical issues have been overcome during the test period, a significant such was the notoriously difficult task of measuring the waste water flow correctly. (As the variation is significant an accurate flow measurement is required in order to evaluate power plant efficiency. Unfortunately that task failed several times delaying the collection of proper data.)

The ORC power plant is installed according to the Swedish Refrigeration Industry Code rigorously addressing the validation of safety [5. KYS 2007]. As the MUNKSJÖ plant at Aspa already had experience from handling ammonia this did not cause any delays to the project.

Fouling and similar issues in heat exchangers was expected but has not been experienced up to the time of writing this paper.

\section{Functional aspects}

The power plant is fully automatic except for restart after fault alarm. In this situation the plant is started remotely by the plant central operations.

Synchronisation between the generator and the grid net is fully automatic. Starting time is 0.5 to 2 minutes to synchronisation and further 1 to 2 minutes to full load.

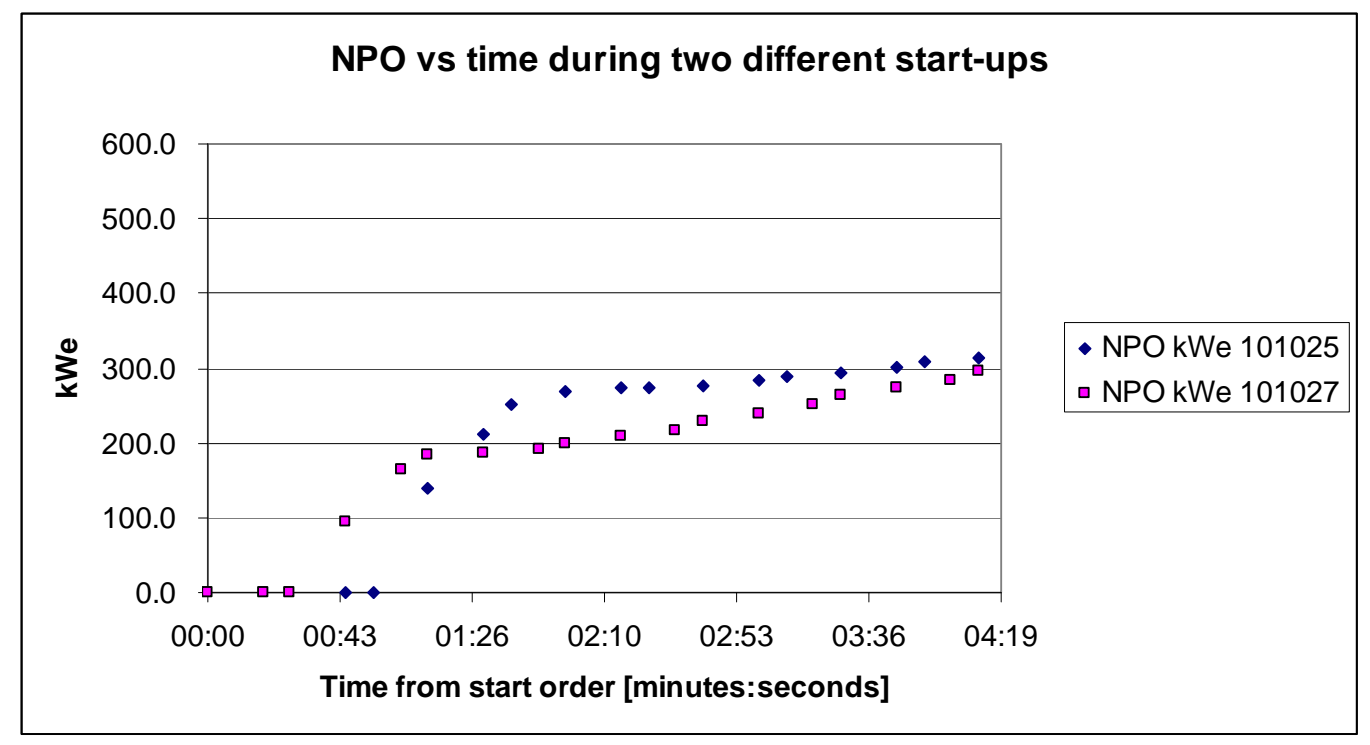

Fig 6. Start-up characteristics during two randomly chosen starts

NPO (Net Power Output) defined as measured at the walls of the ORC-unit, has exceeded predictions mainly due to the lack of heat exchanger fouling.

During the commercial operation availability has been good although the measured period was short. An analysis of the availability will be made after 12 months commercial operation. 


\section{WHR efficiencies}

Electric output ratio, or thermal efficiency, is of little value in determining LTPC-efficiency with finite heat source and heat sink. The size of the ORC has a larger impact on thermal efficiency than the quality of the process or its components, as indicated in [3].

Therefore the Fraction of Carnot and Integrated Local Carnot Efficiency are calculated according to [6. Öhman, H. Lundqvist, P.G.].

As seen in Fig 7 the Integrated Local Carnot Efficiency varies significantly with heat source characteristics $\alpha_{1}$ and heat sink characteristics $\alpha_{2}$.

Note that the Integrated Local Carnot Efficiency is a thermodynamic quality of the combination of heat source and heat sink at each particular operating condition. It is irrelevant of type of process, or efficiency of the process, used for WHR as long as it absorbs an equivalent amount of heat from the heat source.

ETAci

\section{Integrated Local Carnot Efficiency vs alfa1}

(Heat flow from Source 1MW)

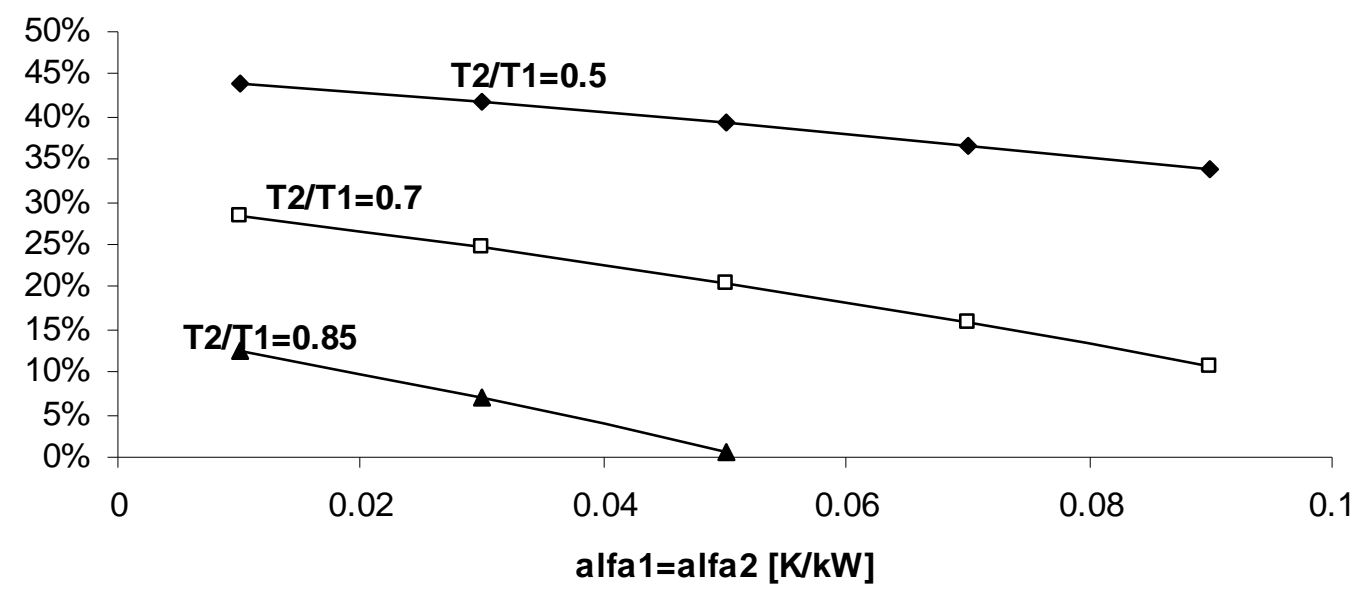

Fig 7. General visualisation of Integrated Local Carnot Efficiency vs $\alpha_{1}$ and $\alpha_{2}$. T1 and T2 are entry temperatures $[\mathrm{K}]$ of a heat source and a heat sink respectively.

Fraction of Carnot is calculated at measured operating conditions by comparing the thermal efficiency with the Integrated Local Carnot Efficiency. FoC shows the true efficiency of the WHR as compared to the theoretical potential with regards only to the heat source and heat sink. 


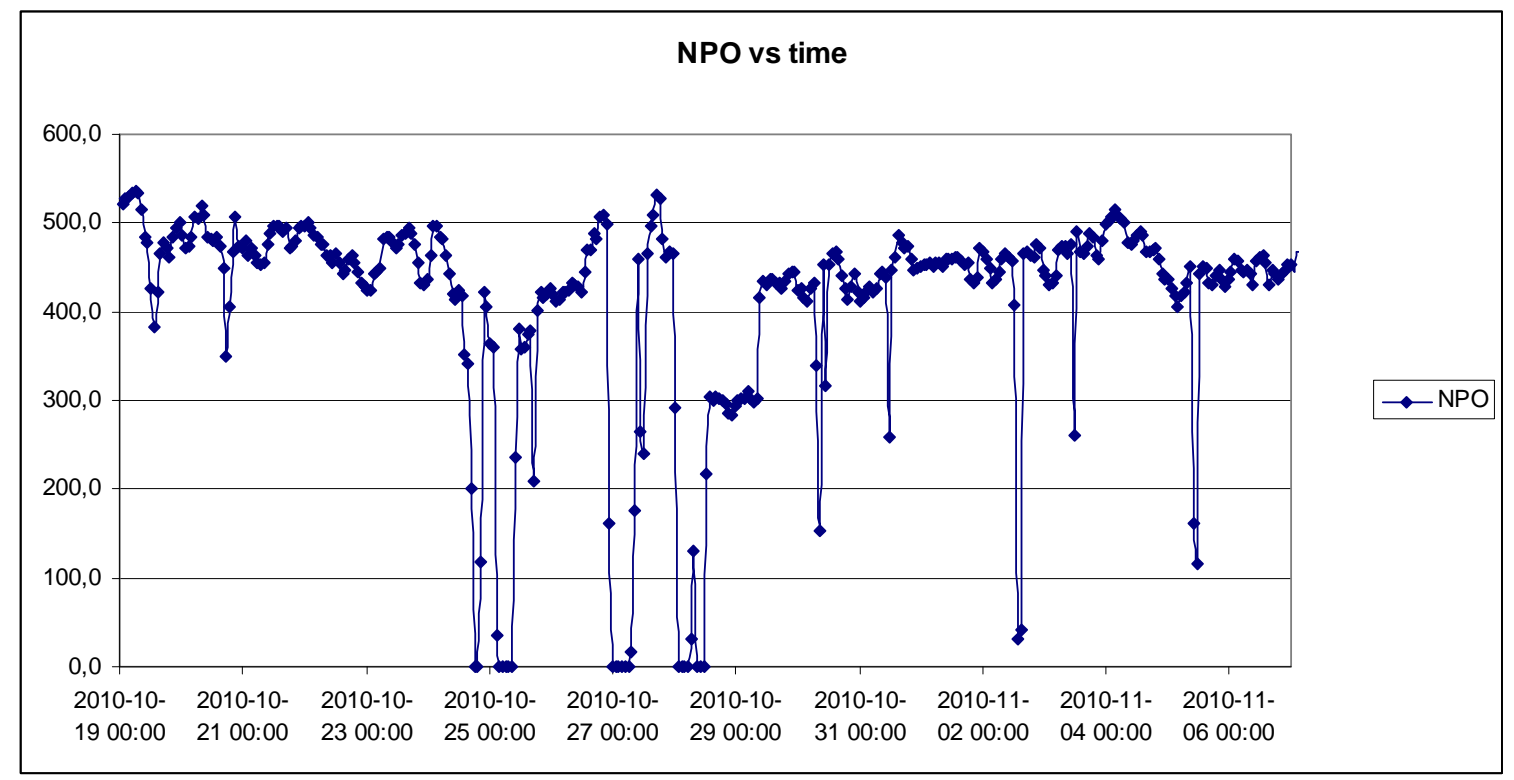

Fig 8. NPO (kWel) vs time during the time studied

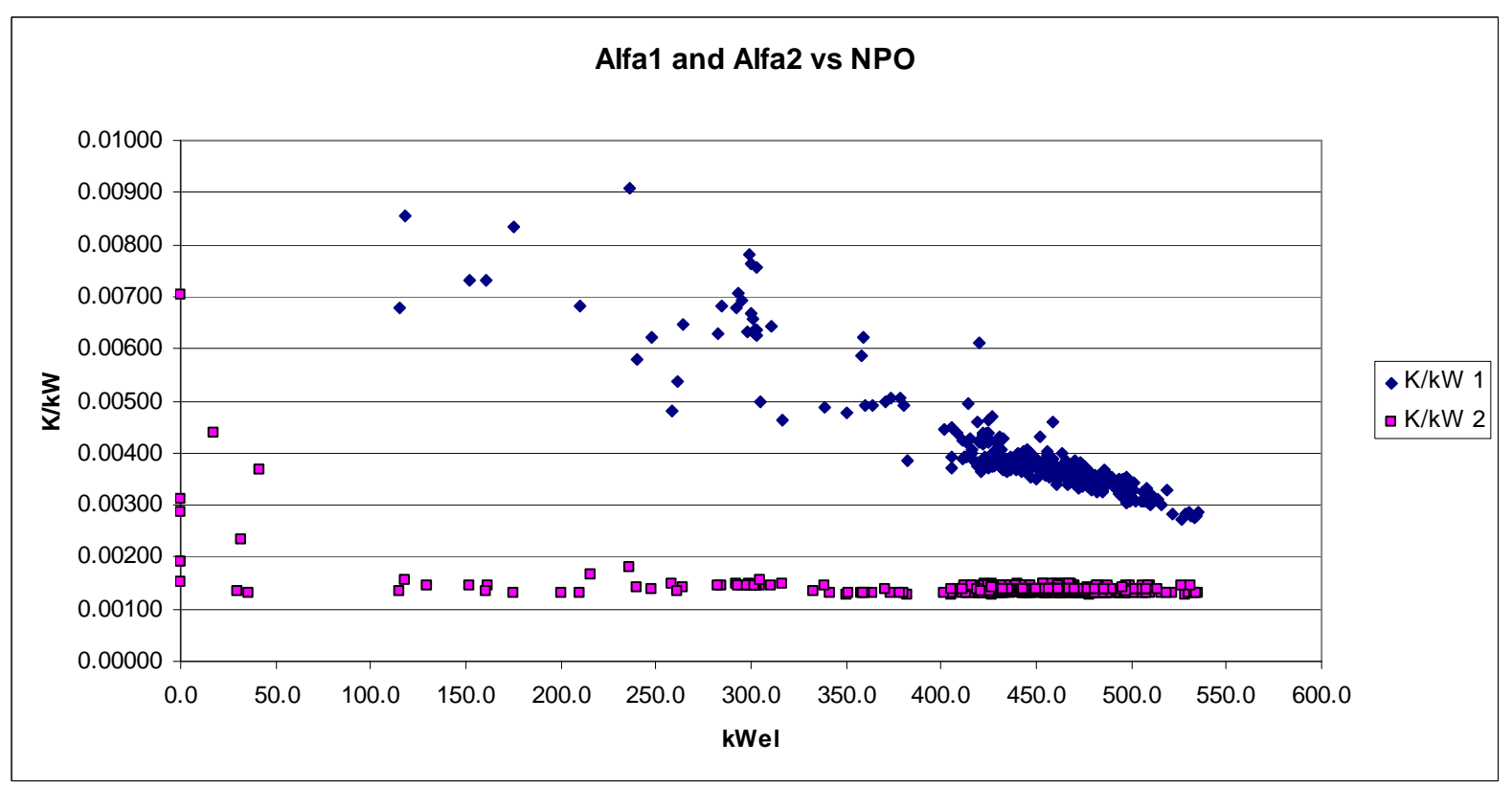

Fig 9. $\alpha_{1}$ and $\alpha_{2}$ vs NPO during the time period 


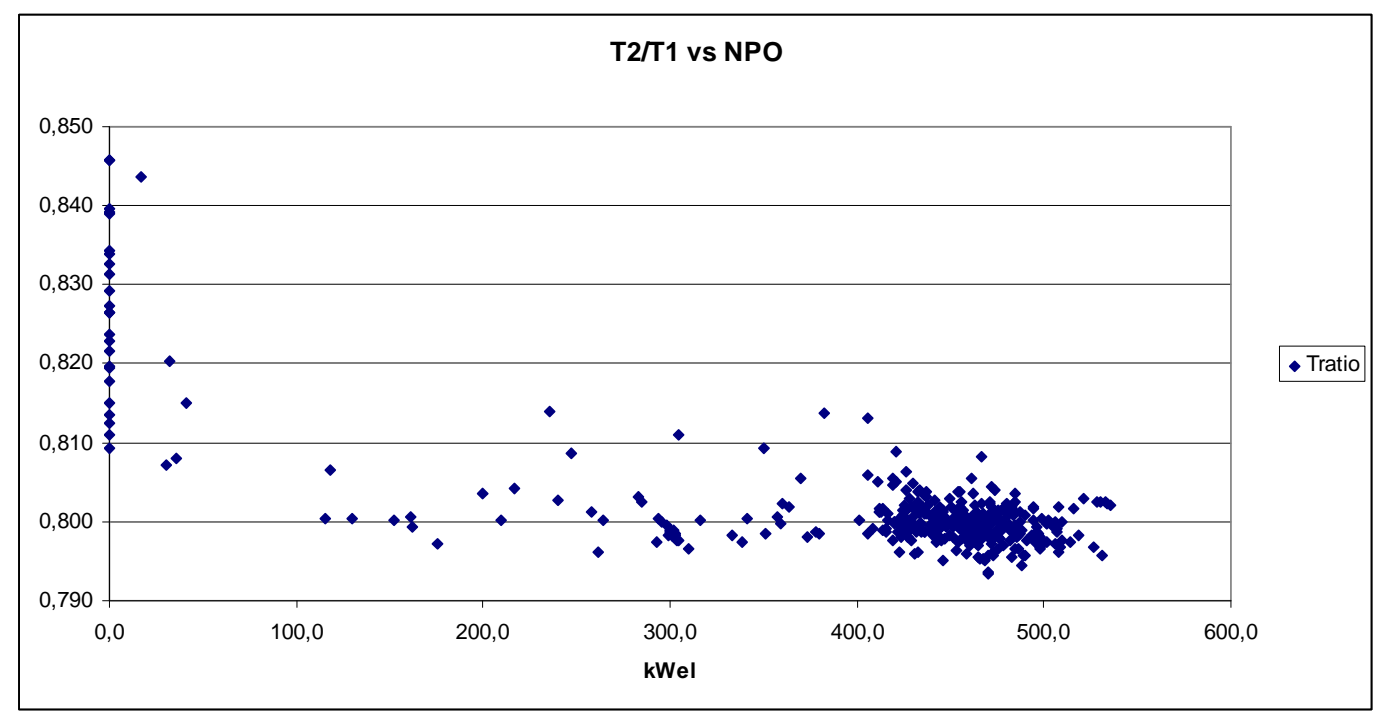

Fig 10. T2/T1 vs NPO during the time studied

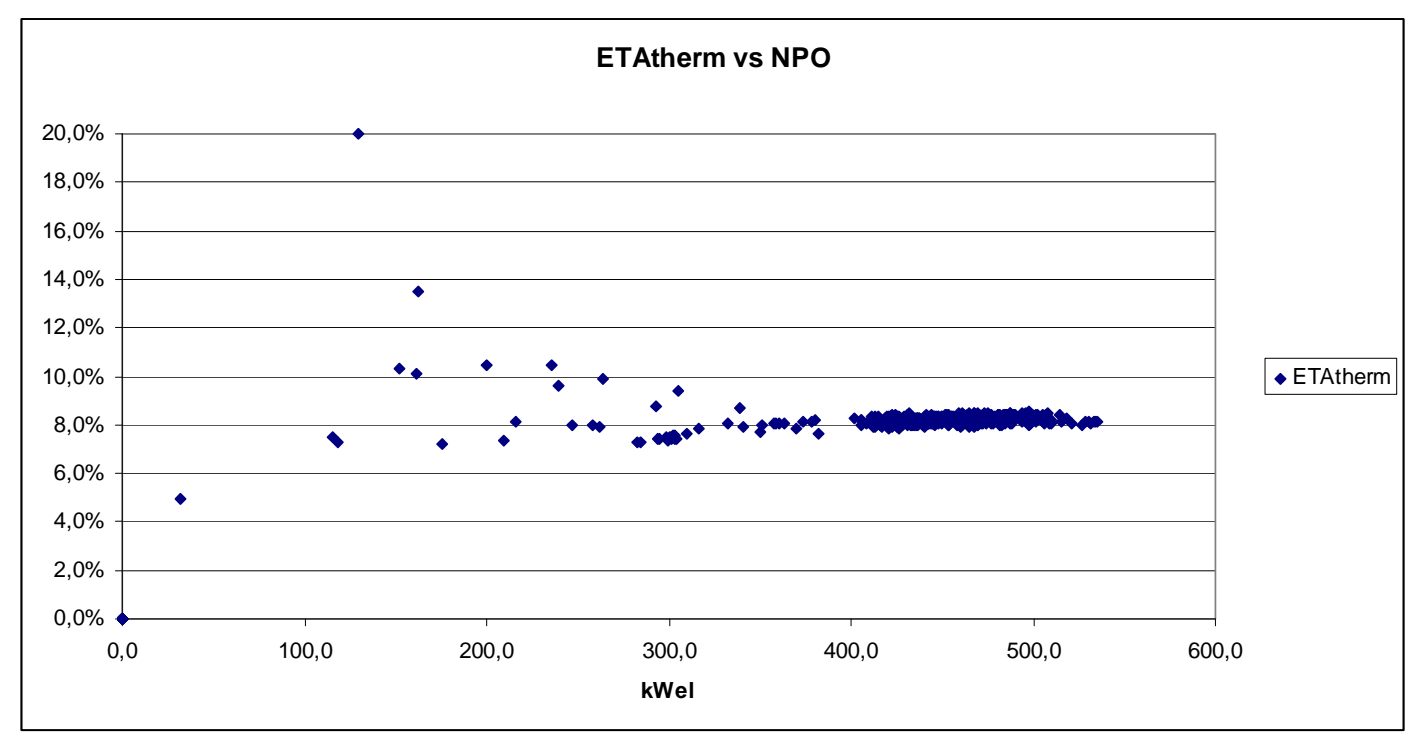

Fig 11. $\eta_{\text {therm }}$ vs NPO during the time studied

From Figures 9 to 11 the following data was extracted for further analysis of the FoC.

\begin{tabular}{|l|l|l|l|l|l|l|}
\hline NPO & $\alpha_{1}$ & $\alpha_{2}$ & T2/T1 & $\eta_{\text {therm }}$ & $\eta_{c I}$ & FoC \\
\hline $525 \mathrm{kWel}$ & 0,0028 & 0,0013 & 0,795 & $8,2 \%$ & $16,6 \%$ & $49,4 \%$ \\
\hline $500 \mathrm{kWel}$ & 0,0033 & 0,0013 & 0,795 & $8,4 \%$ & $16,5 \%$ & $51,0 \%$ \\
\hline $475 \mathrm{kWel}$ & 0,0035 & 0,0013 & 0,80 & $8,4 \%$ & $16,8 \%$ & $50,0 \%$ \\
\hline $450 \mathrm{kWel}$ & 0,0038 & 0,0013 & 0,80 & $8,3 \%$ & $16,8 \%$ & $49,4 \%$ \\
\hline $425 \mathrm{kWel}$ & 0,0039 & 0,0013 & 0,80 & $8,2 \%$ & $16,6 \%$ & $49,3 \%$ \\
\hline
\end{tabular}

Table 3. Aggregation of the measured performance data and corresponding FoC 


\section{Evaluation of WHR efficiency}

The obtained FoC can be compared to the general performance prediction of an Organic Rankine Cycle with Saturated expansion inlet ORCS.

A general simulation of FoC is performed at $\alpha_{1}=0,0035, \alpha_{2}=0,0013, \mathrm{~T} 1=82^{\circ} \mathrm{C}, \mathrm{T} 2=11^{\circ} \mathrm{C}$ and internal process efficiencies chosen as reversible, high, average and low internal process efficiencies, se Table 4.

\begin{tabular}{|l|l|l|l|l|l|}
\hline & Reversible & High & Average & Low & Comment \\
\hline $\begin{array}{l}\text { External pumping } \\
\text { efficiency }\end{array}$ & $100 \%$ & $95 \%$ & $90 \%$ & $85 \%$ & Ex, motor air cooling \\
\hline $\begin{array}{l}\text { Internal pumping } \\
\text { efficiency }\end{array}$ & $100 \%$ & $95 \%$ & $75 \%$ & $50 \%$ & $d h($ isentropic) $/$ dh(real) \\
\hline $\begin{array}{l}\text { External expansion } \\
\text { efficiency }\end{array}$ & $100 \%$ & $95 \%$ & $90 \%$ & $85 \%$ & $\begin{array}{l}\text { Ex, alternator air } \\
\text { cooling }\end{array}$ \\
\hline $\begin{array}{l}\text { Internal expansion } \\
\text { efficiency }\end{array}$ & $100 \%$ & $95 \%$ & $75 \%$ & $50 \%$ & dh(real $/$ dh(isentropic) \\
\hline$d T$ boiler & $0^{\circ} \mathrm{C}$ & $1{ }^{\circ} \mathrm{C}$ & $3^{\circ} \mathrm{C}$ & $5^{\circ} \mathrm{C}$ & $d T$ at critical pinch \\
\hline$d T$ condenser & $0^{\circ} \mathrm{C}$ & $1{ }^{\circ} \mathrm{C}$ & $3^{\circ} \mathrm{C}$ & $5^{\circ} \mathrm{C}$ & $d T$ at critical pinch \\
\hline
\end{tabular}

Table 4. Assumed internal process efficiencies for an ORCS for reference purposes, see [6]. Efficiency is divided in to kinds: External efficiency means that heat from losses is emitted externally to the atmosphere. Internal efficiency means that heat from losses is internally absorbed by the operating fluid.

Fig12 shows the simulated results side by side with the real results from the ORC power plant in Aspa. As can be seen the result indicates that the Opcon Powerbox in MUNKSJÖ paper mill performs very similarly to a high internal process efficiency ORCS with regards to waste heat recovery efficiency.

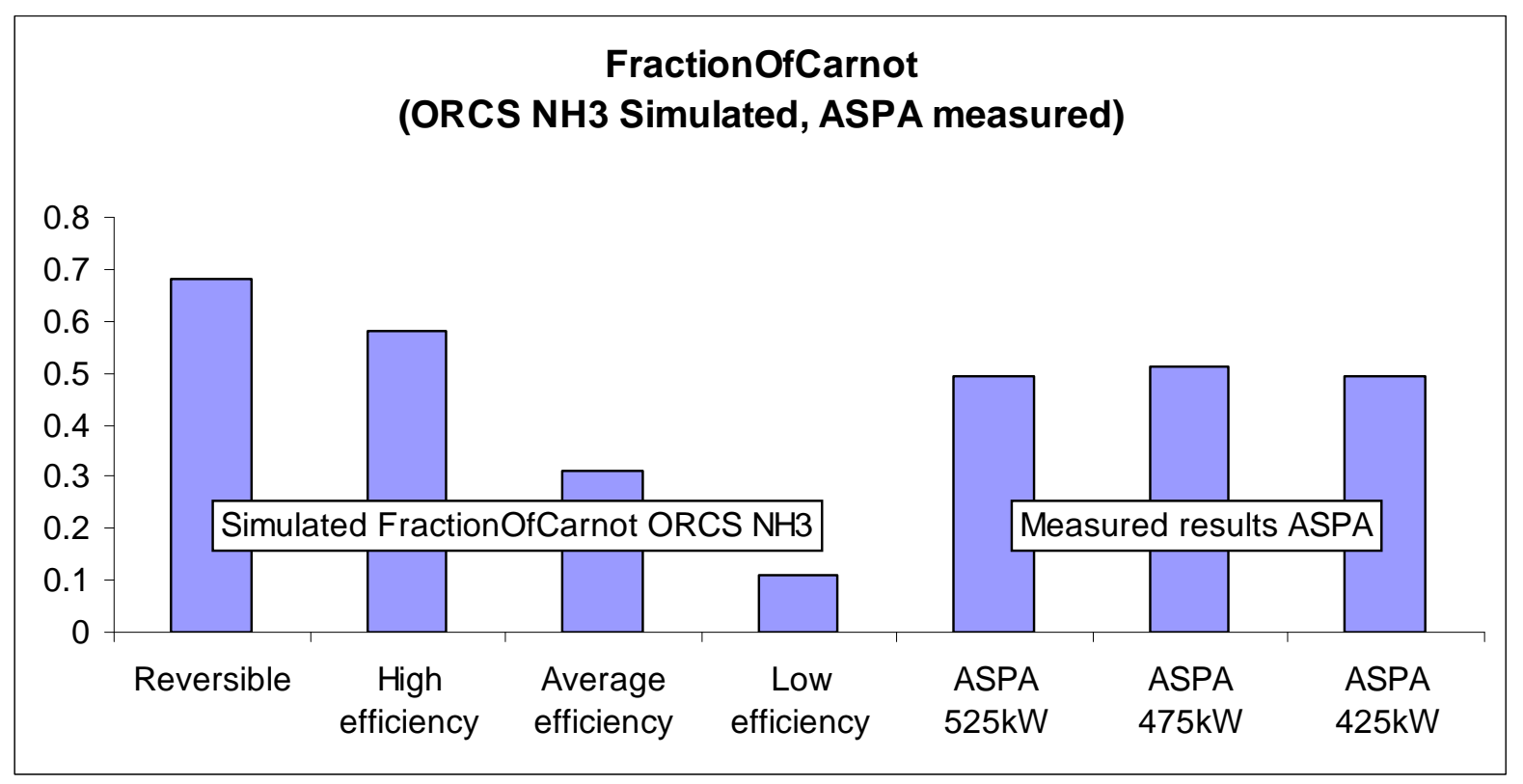

Fig 12. FoC at real operating conditions. (Reversible, High, Average, Low and Measured) 


\section{Evaluation of part load performance}

The thermal efficiency vs NPO is a significant indicator on part load efficiency. Fig 11 indicates an efficiency variation of $3 \%$ in the NPO range from $100 \%$ to $65 \%$. Though the results are less concentrated below 65\% Fig 11 indicates roughly constant thermal efficiency down to $20 \%$ power generation.

Table 3 shows that in the range of $425-525 \mathrm{kWe}$ the Fraction of Carnot is fairly constant. As $\alpha_{1}$ is very stable, Fig 9 , this means that the system is insensitive to the variations in $\alpha_{2}$ as shown in the same figure. $\alpha_{2}$ represents the variations in waste water conditions.

\section{Economy}

The WHR-unit was supplied by Opcon and is owned and operated by the utility company Boxpower AB. Boxpower sells a minimum of 3133MWh/year, to MUNKSJÖ at a fixed price/kWh while MUNKSJÖ supplies a guaranteed minimum amount of warm and cold water.

This arrangement means that MUNKSJÖ is able to hedge its power costs without the necessity to invest in equipment. Furthermore it gives an incentive to Boxpower $\mathrm{AB}$ to operate the unit as productively as possible.

A more conventional sale/purchase arrangement was originally offered from the supplier.

Though such an arrangement was fully satisfactory, enabling a Pay-off time of 3 years, MUNKSJÖ valued the opportunity to hedge the cost for electric power instead of purchasing and operating the equipment themselves.

Quotation data:

Technical life:

Costs of materials and installation: $\quad 12 \mathrm{MSEK}$

Depreciation:

Interest rate:

10 years

$5 \%$

Cost for yearly maintenance was in the same order as the savings in plant process maintenance due to the WHR-installation, therefore it could be ignored in the investment analysis. SEK/EURO exchange rate was 10,3 SEK/EURO at the time of quotation.

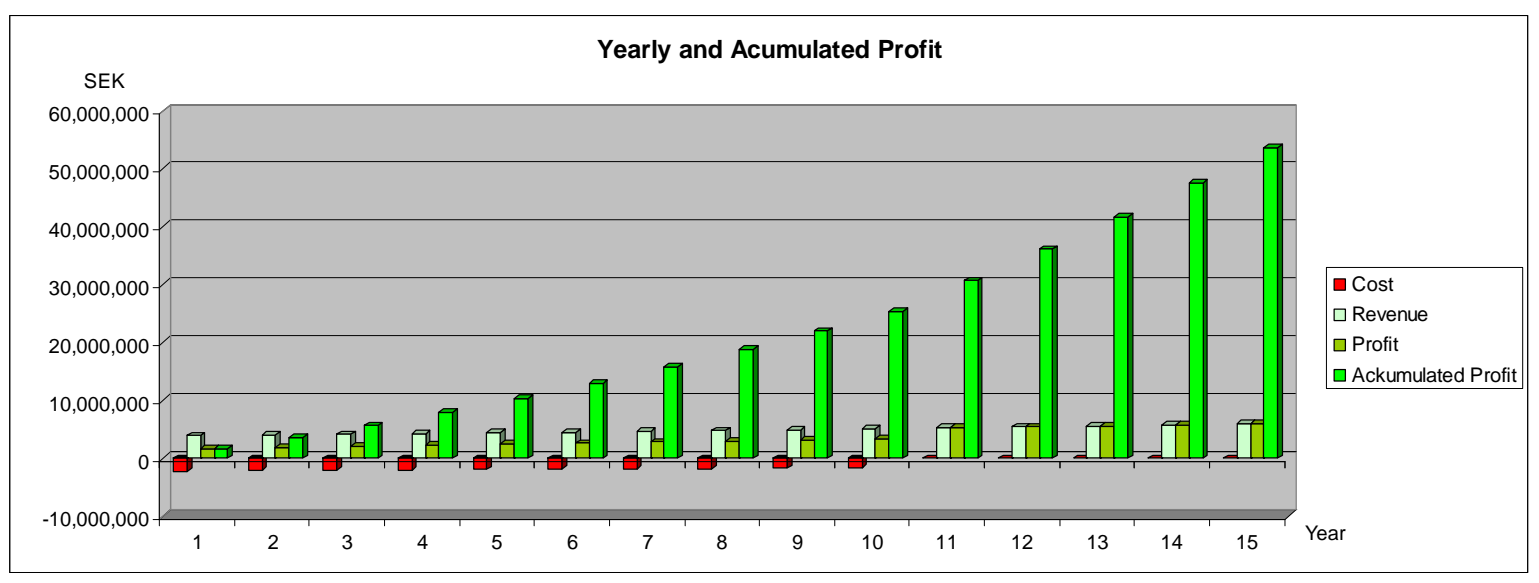

Fig 13. Investment case using quotational data calculated at electric price of $1 \mathrm{SEK} / \mathrm{kWh}$. The investment case shown is profitable from the first year of operation. 
Using the above quotational information a yearly average NPO of $460 \mathrm{kWe}$ would give a straight Pay-back time of 3 years. Fig 8 indicates the possibility of achieving that though longer time of operation is required for that conclusion.

\section{Conclusions}

The WHR-system at the MUNKSJÖ pulp mill in Aspa, Sweden shows high efficiency, insensitivity to variations in waste water conditions and allow for a profitable arrangement between the utility company and the pulp mill.

The complexity of the waste water conditions has, until finalizing this article, not caused any trouble.

The results are encouraging with regards to the utilization of other process industry waste heat streams.

Further investigations are required after about 1 year of operation in order to evaluate availability.

\section{References}

1. Brasz, J.J., Holdmann, Gwen, Power Production from a Moderate -Temperature Geothermal Resource, paper presented at the GRC annual meeting, Reno, Nevada, September 25-28, 2005.

2. Öhman, H. Hedebäck, P 2008 "Electricity from waste heat already at a low $55^{\circ} \mathrm{C}$ " Conference proceedings p. 228-230, World Boienergy 2008, ISBN 978-91-927624-0-3

3. Timuska, K. 2008 "100 years of energy efficiency” http://www.opcon.se/web/History_4.aspx

4. Öhman, H. "Test results of a screw type expander/compressor and the implication of phase separators on the refrigeration process" International Refrigeration and Air Conditioning Conference at Purdue, R025, July 12-15, 2004

5. KYS “Aggregat med Ammoniak” Säkerhetsanvisningar för kyl- och värmepumpaggregat. Svensk Kylnorm, 2007, utgåva 1

6. Öhman, H. Lundqvist, P.G "Theory and method for analysis of low temperature driven power cycles” Journal of Applied Thermal Engineering (In peer review at time of submitting this paper) 